April, 2011

Calle Madrid, 126

28903 Getafe (Spain)

Fax (34) 916249875

\title{
DOES IMMIGRATION CAUSE CRIME? EVIDENCE FROM SPAIN•
}

\author{
César Alonso-Borrego \\ Universidad Carlos III and FEDEA
}

Nuno Garoupa

University of Illinois

Pablo Vázquez

Universidad Complutense and FEDEA

\begin{abstract}
The relationship between crime and immigration has been a matter of controversy in the US and around the world. This paper investigates empirically the case of Spain. From 1999 to 2009, Spain has had a large wave of immigration from different areas of the globe. At the same time, crime rates have increased. However, by comparison with other European countries that have received similar massive immigration waves during the same period, crime rates in Spain have increased less considerably. We show that there is a significant relationship between crime and immigration. Nevertheless, the explanation is found in the specific characteristics of the different immigration groups, particularly in the amount and type of human capital, which is a result largely in tune with previous studies on US immigration and crime.
\end{abstract}

- This paper is based on a larger project developed by FEDEA on the economics and sociology of immigration in Spain (2008). Garoupa acknowledges the financial support of the European Commission, MMECC (EC Project 044422) and Alonso-Borrego acknowledges the financial support of the Spanish Ministry of Science and Innovation (Grant ECO200911165). We are grateful to John Donohue, Michele Boldrin, Antonio Cabrales, Raquel Carrasco, Marco Celentani, Marcelo Perera and Giulio Zanella for helpful comments on previous drafts. Mario Alloza, Brindusa Anghel, Yeny C. Estrada and Roya H. Samarghandi provided excellent research assistance. The usual disclaimers apply. 


\section{Introduction}

Immigration and crime are related very frequently within the media, political discussions, and even in daily conversation. The opinion polls in many countries show an increasing concern for the perceived correlation between immigration and crime.

This paper contributes to the growing empirical literature on immigration and crime, with a particular application to Spanish data. Although the relationship between crime and immigration has been the focus of much political debate, the economic and empirical literature is not vast. Some studies have looked into US data, but they seem to point out that immigration and crime do not present a consistent pattern. ${ }^{1}$

The situation of the European Union is different from that of the US. Until the late 1990s, immigration from outside of the Union was not very significant. Furthermore, in the context of the EU Member-states, Spain might be regarded as a particular case. Spain had an important but not dramatic increase in crime rates while there was a very significant growth in immigration in a short time span. The interesting puzzle is to reconcile such a finding with the alleged fact that there is a strong correlation between crime and immigration.

The most obvious response to this puzzle is that there is no causal relationship between immigration and crime in Spain. However, this relationship does exist and is quite significant in our econometric analysis. Immigration partially explains the evolution of the crime rates in Spain in the last decade or so, demonstrating conclusively that both phenomena are related to a significant extent.

A second possible interpretation relies on the period of economic growth in Spain observed in the last ten years, and the consequent development of the labor market for immigrants in Spain. Unlike other EU countries (such as Italy, France or Portugal), Spain has experienced a long

1 See, among others, Borjas et. al. (2006), Butcher and Piehl (1998a, 1998b, 2005), Card (2001) and Moehling and Piehl (2007). 
period of economic growth since the mid 1990s. Economic growth has provided for better legitimate economic opportunities in the labor market for everyone. At the same time, it has led to an increase in new opportunities for both natives and immigrants to commit crimes (in particular, property and economic crimes). There is a potential substitution effect with an ambiguous outcome. Cross-country comparisons are not helpful to determine how this substitution effect should operate. For example, Spain and Ireland share a high rate of economic growth during this period but differ in terms of their increase in crime rates. On the contrary, Italy and Greece have significantly lower entry of immigration and worse growth rates in the period 2000 to 2006 , and yet they present similar patterns to Spain with respect to crime rates.

On the other hand, and focusing exclusively on the case of Spain, the evolution of the different types of crime does not have a consistent relationship with the rate of unemployment, as shown in Figure 1. Additionally, one has to remember that a major portion of the immigrant population has entered the country illegally and have remained illegal until an official regularization has taken place. These regularizations have occurred twice but have apparently not affected significantly crime rates. ${ }^{2}$

\section{$<$ INSERT FIGURE 1 HERE $>$}

We need a more sophisticated explanation. We suggest our puzzle can be solved by concentrating on the types of immigrants coming into the country. The bulk of the thesis is that Spain has received immigrants that, because of their characteristics (i.e., age, gender, education, and culture), are less likely to commit crimes. We refer to this explanation as cultural proximity.

2 Two regularization amnesties took place in 2000 and 2005 in order to solve the situation of illegal immigrants. The amnesty of 2000 required entry in to Spain before June 1999, an expired permit of residence or working permit, and no criminal record. Almost a quarter of a million people benefited from this legal reform. The amnesty of 2005 only required having a job or an offer of a job in Spain (an employment contract for at least six months). Almost six hundred thousand people benefited from this second amnesty. 
Immigration in Spain is a phenomenon that is extremely heterogeneous. By that we mean that immigration to Spain encompasses very different realities, from a retired German woman who spends her retirement pension in Spain to a young Ecuadorian man who works in construction to help his family back in his native country.

Our hypothesis is that the specific composition of the immigrant population determines the degree of correlation between immigration and crime to a great extent. In the particular case of Spain, a large proportion of the immigrant population has characteristics that make them less likely to commit crimes than otherwise.

Obviously, it could be that the process of integration is particularly adequate and successful in Spain. An adequate and successful integration policy could substantially reduce crime rates that are explained by immigration elsewhere. Depending on their cultural upbringing, immigrants usually could be more or less inclined to criminal activities depending on institutional characteristics of each native country. Nevertheless, in those countries where immigrants are better integrated, it is expected that fewer criminal offenses are committed.

On Table 1, we show the rate of homicides per thousand habitants - a crime easily comparable for the purpose of criminal law specifics - of people with different nationalities in their country of origin and in Spain. If we look at each continent individually, one has very different rates of homicide even though the proportions in Spain and in the countries of origin are fairly similar, as seen in Column 3. At the same time, the differences across continents of origin can indicate that different nationalities represent a distinct attitude towards crime which might not have been eliminated by the process of integration. ${ }^{3}$

\footnotetext{
${ }^{3}$ In the period 2000-2009, the nationalities with the highest annual immigration rates are, by order of magnitude, Moroccans, Ecuadorians, Romanians and Colombians. The nationalities with the highest annual crime rates are, by order of magnitude, Algerians, Romanians and Moroccans. Colombians, Ecuadorians and Peruvians follow significantly below.
} 
On Table 2, we present some statistics about different crimes and the origin or nationality of the immigrants arrested for such crimes. We can immediately see that there are significant variations across nationalities and across crimes.

\section{<INSERT TABLE 2 HERE>}

In this study, we present an empirical analysis that aims at responding conclusively to these issues ${ }^{4}$ In section two, we discuss the economic model of criminal behavior that provides the theoretical foundation for the main hypothesis. In section three, we test econometrically the hypothesis and, in section four, we discuss the empirical results. Section five concludes.

\section{Economic Models of Criminal Behavior}

The economic model of crime (Becker, 1968; Garoupa, 1997; Polinsky and Shavell, 2000) is based on the rational comparison between the benefits and the costs of committing an offense. Under-compliance with the law arises when the benefits of compliance are lower than the costs. Usually the benefits of a crime include the illegal gain obtained by the criminal whereas the costs include the probability and severity of punishment (although the economic model has been extended to include other factors). The approach in the economic model is to hypothesize that everyone is a potential criminal, however only a subset of the population does indeed commit crimes. As a result, the economic model does not provide any particular argument for why immigrants should under-comply with the law more or

\footnotetext{
${ }_{4}$ Previous work with Spanish provincial data on crime, but disregarding immigration, includes Buonanno and Montolio (2008). For the Italian case, see Bianchi et. al. (2008) and Buonanno et. al. (2009).
} 
less frequently than natives, except that their profile of benefits and costs of crime could be different from that of natives.

In this context, from a theoretical perspective, there are countervailing arguments about the higher or lower propensity of immigrants towards crime with respect to natives, based on their profile of costs and benefits. However, the strength of these arguments depends obviously on empirical confirmation. Only a serious and rigorous empirical analysis can decide which reasons do actually prevail in reality.

The first argument is that, due to difficulties in the labor market and for lack of economic opportunities, the illegal gain obtained by immigrants is relatively higher than that of natives. In other words, it could be that immigrants have less to lose than natives from noncompliance with the law. The argument is based on the income/employment status of the individual; that is to say, it has nothing to do with the particular attribute of being an immigrant, but with the fact that a higher proportion of the immigrant population has economic problems or has fewer economic opportunities. ${ }^{5}$

A second argument looks at cooperative crimes that require a close network of trust and coordination. The economic literature has discussed how organized crime can develop mechanisms of control and quality assurance (Garoupa, 2007) and has identified ethnic homogeneity as a very powerful mechanism to guarantee the success of a criminal organization. Ethnic and family ties reduce opportunism and hold-ups in the criminal network, therefore achieving the necessary levels of trust for a profitable and lucrative criminal enterprise. In that respect, homogeneous and closed immigrant communities can be an attractive focal point for these activities. ${ }^{6}$ Hence, it would be no surprise if criminal enterprises or gangs on prostitution, drugs, money laundering, and traffic of weapons, women or

\footnotetext{
5 In a fully rational model, labor market arguments could explain overall crime rates. However, in a bounded rational model such as the one endorsed by behavioral law and economics, labor marker arguments should be more relevant to explain property crime and those crimes more directly pursued for economic reasons.

6 The same argument also explains why certain (legal) business activities and enterprises that require trust and coordination attract immigrant communities. Hence, we would expect immigrant communities to be more engaged in criminal activities and in certain entrepreneurial activities.
} 
babies were dominated by immigrants. The closeness of immigrant communities provides the necessary and trustworthy link between the home and the resident countries. These effects will necessarily be reduced when the immigrant community becomes better integrated in the resident country and grows larger. It is true that larger cities (such as Barcelona or Madrid in Spain, or New York and Chicago in the US) facilitate the search of contacts that might help the expansion of criminal activities. However, an integrated and large immigrant community will lose the homogeneity and closeness that makes it attractive for criminal enterprises of this type. In summary, for criminal activities that require coordination and trust, we should expect to find a disproportional representation of immigrant communities. ${ }^{7}$

A third argument relies on the cost of under-compliance. It has been documented by legal economists (McAdams, 2000) that compliance with the law is easier to achieve when it embodies social norms shared by most individuals in a community and when it triggers psychological reactions that limit criminal opportunism (because individuals are socialized in a culture that inculcates since childhood that certain behaviors are just wrong). We can talk of under-compliance due to different cultural perceptions. Examples could include terrorist acts, gender violence or antisocial behavior, where asymmetries of social norms and cultural values could generate different perceptions about not only the law, but also the fairness and general acceptance of the law. As perceptions converge, either because the immigrant community internalizes the national social norms due to successful integration or because the law is reformed to accommodate

\footnotetext{
7 There is no detailed evidence we can use in our dataset to test this hypothesis. According to the Spanish Office of the Chief Prosecutor, there were 482 criminal organizations in 2006 (compared to 594 in 2002 and 494 in 2004). Three groups are quite significant: Colombians (142 organizations), Moroccans (108 organizations) and Romanians (92 organizations). The Office of the Chief Prosecutor points out that these ethnic organizations are quite consolidated and are responsible for a large proportion of the crimes committed by illegal organizations in Spain. While the Moroccan and Romanian organizations largely operate in all criminal markets, the Colombians focus on the market for narcotics and related activities (money laundering, corruption and violence).
} 
the diversity of perceptions, this type of under-compliance will tend to be mitigated.

A fourth argument could be less knowledge of local laws. Immigrants could violate the law by mistake more frequently simply because they ignore the law or are unaware of the specific enforcement choices of national authorities. Ignorance of the law is no excuse in a court of law, but it may nevertheless lead to more frequent criminal behavior among immigrants than among natives. Presumably, this argument can only be relevant for those areas of the law that require a degree of sophistication that make it more difficult for the immigrant community to immediately grasp the substance and the procedure of local laws. This could include, for example, antisocial behavior, traffic offenses, consumption of illegal substances, and so on.

A final argument has to do with risk aversion. If criminals have a less risk averse utility profile (Becker, 1968), it may be that immigrants are on average closer to such profile than natives because there is a selection effect due to immigration. The latter being, intrinsically, a risky activity; presumably only people with lower risk aversion become immigrants. However, notice that the underlying risks, for immigration and for crime, are different and hence the selection effect could well not be very relevant (Bianchi, Buonanno, and Pinotti, 2008).

So far we have identified reasons for why immigrants could be more prone to commit certain crimes. They include the labor market and general economic conditions, need for cooperation and trust, costs of undercompliance due to different cultural perceptions, less knowledge of local laws, and (less convincingly) lower risk aversion.

However, there are also good economic reasons for why immigrants could be less prone to commit other types of crime. One obvious reason has to do with opportunities. First, earning potentials could be higher for immigrants, so that the lost legal earnings due to criminal activities could be more significant as a deterrent. Second, if immigrants tend to be located in more depressed economic neighborhoods, then they have fewer 
opportunities for property crime. Third, even if economic well-being determines that immigrants could be more likely to commit certain economic crimes, it is also likely that those crimes that require specific levels of human capital or technology will be committed less by immigrants (for example, regulatory and administrative crimes). Another line of reasoning could be that if immigrants have certain distinct characteristics that make them easier to be targeted by the enforcement authorities, then they could be more deterred since the expected severity of punishment could be higher. Furthermore, the risk of deportation could make punishment more costly. Finally, less knowledge of local laws could drive them to comply due to overestimating punishment.

As we have seen, there is no economic theory that provides support to the hypothesis that there is a strong correlation between crime and immigration. In fact, the economic arguments about differential behavior towards crime among natives and immigrants are mixed. Furthermore, the sign and the degree of correlation between crime and immigration is expected to differ by crime types. If there exists a linkage between immigration and certain crime types, it is probably better explained by incentives that factor into opportunism rather than by any specific attribute of the immigrant community.

Given the relevant explanations and the available data for the Spanish economy and society, we suggest that the economic theory at its best proposes a very weak positive correlation between general crime rates and immigration. The theoretical reasons for more crime (labor market and general economic conditions, need for cooperation and trust, costs of undercompliance due to different cultural perceptions, less knowledge of local laws, and lower risk aversion) might weakly dominate the theoretical reasons for less crime (opportunity costs, information available, access to technology). In summary, we suggest that, focusing on the criminal data published by the Spanish authorities, the arguments for a positive 
correlation are likely to be more relevant than the arguments for a negative correlation. ${ }^{8}$

Notice, however, that we hypothesize a weak positive correlation, the argument being cultural proximity. Immigrants with cultural proximity to the Spanish society will have a profile of preferences akin to natives. Therefore, the economic model should predict that differences in criminal behavior cannot be significant.

The possible testable hypothesis we suggest is that crimes committed by immigrants can be explained by labor market conditions and economic opportunities. Education might also be used as a proxy for knowledge of local laws and reliance on closed ethnical groups; hence higher levels of education should reduce crime. Age and gender is also relevant for the (unconditional) probability of under-compliance; in particular young males are responsible for most law infractions. Urban areas could have an important impact because they reduce the probability of detection but also the likelihood of strong ethnic ties. At the same time, following the criminal proximity argument, the presence of Spanish speaking immigration should decrease the incidence of criminal behavior.

\section{Econometric Approach}

As discussed in the previous section, the baseline economic model we use lies on the traditional choice-theoretic approach at the individual level, as discussed in the previous section (Becker, 1968; Ehrlich, 1973). At each period $t$, each individual $i$ decides whether or not to commit a crime. Each

\footnotetext{
8 Immigrants can also be disproportionally affected by crime as victims. There is no similar sophisticated economic model for victimization of crime. In fact, a major criticism to the economic literature of crime is that it is oriented to deterrence and seriously neglects the role of the victim (Garoupa, 1997). However, from a theoretical perspective, we can also consider possible reasons for why immigrants could be the targets of crimes more often than natives. One obvious example is hate crimes, crimes motivated by racism or xenophobia (Dharmapala and Garoupa, 2004). Another example is crimes related to the legal status or regulation of immigration such as corruption in obtaining residence permits or other type of extortions for social benefits. Finally, crimes committed within closed ethnic homogeneous groups could also affect immigrants in a disproportional way. The available data for Spain does not allow us to test any of these possible explanations.
} 
individual lives in a particular location 1 , being assumed that a person only commits crimes within the location of residence. Defining $Y_{i t}$ as a binary variable that takes the value of 1 when individual $i$ commits a crime and 0 otherwise, the probability that individual $i$ commits a crime at period $t$ can thus be written as

$$
\operatorname{Pr}\left(Y_{i t}=1 / Z_{1 t}, X_{i t}\right)=F\left(X_{1 t^{\prime}} B+X_{i t}^{\prime} Y^{+} \mu_{i t}+\eta_{i t}\right)
$$

where $X_{l t}$ is a vector of observable location-specific characteristics and $X_{i t}$ is a vector of observable individual-specific characteristics; such locationspecific and individual-specific characteristics might affect the opportunity costs of committing a crime with respect to engaging in legal economic activities. In addition, there can be further individual-specific and locationspecific characteristics, denoted respectively by $\mu_{i t}$ and $\eta_{i t}$, potentially affecting the individual's decision of crime commission, which nonetheless are unobserved by the researcher. Among the individual variables, it is of particular interest to consider whether the individual is an immigrant or not, even including his specific nationality. We should also consider the level of education, age, gender, etc. As to the location-specific variables, we consider the Spanish province in which the individual lives, and whether the individual resides in an urban or rural area (or the size of the municipality in which the individual resides). Also, economic characteristics of the location, such as the unemployment rate and the per capita income, provide a measure of the economic prospects of their residents in the legal labor market.

In addition, we are concerned with individual's criminal experience, a relevant aspect already discussed in the literature (Sah, 1991; Glaeser et al., 1996; Fajnzylber et al., 2002; Grogger, 1995). This factor has a potential relevance regarding the relative cost of entry in criminal activity, the learning curve, and the economic opportunities for recidivists in the legal labor market. Consequently, the probability of crime commission can be written as

$$
\operatorname{Pr}\left(Y_{i t}=1 / Z_{1 t}, X_{i t}\right)=F\left(\delta Y_{i, t-1}+X_{l t}^{\prime} B+X_{i t}^{\prime} Y^{+} \mu_{i t}+\eta_{i t}\right) .
$$


To estimate this model, we would ideally use a representative sample of the population, yet, as is usually the case, there is not individual-level data available. Instead, we must rely on aggregate data by geographic locations. Our location units are the fifty Spanish provinces. ${ }^{9}$ The use of province-level data involves data aggregation among individuals within each location unit, as well as several statistical assumptions, which are treated in detail for the empirical studies about crime by Durlauf et al. (2010). ${ }^{10}$ The underlying conditional probability for individual crime action is implicitly characterized by a linear probability model.

The consequence of using aggregate data at the province level is that the dependent variable is no longer the probability that an individual will commit crime. Instead, it turns out to be the crime rate, i.e., the number of criminal acts relative to the province population. Also, when aggregating whether each individual within a province committed a crime in the previous year, we will get the lagged crime rate. Each of the explanatory variables related to a particular individual characteristic will shape the proportion of people living in the province with such characteristic after aggregating.

The explanatory variables will consist of the lagged crime rate, the proportion of immigrants in the province (which will be further broken down by country or geographic zone of origin), the province rate of unemployment of these groups (including that of the nationals), the proportion of individuals in each collective with a given level of education, the proportion of the population that lives in urban areas, and the proportion of individuals

9 At the administrative level, Spain is broken down into fifty provinces and two autonomous North-African cities, Ceuta and Melilla, which were excluded from the analysis because of their different idiosyncrasy due to their geography and history.

10 In addition to the usual parameter homogeneity assumption, for the model to preserve the interpretation of the baseline behavioral model at the individual level, it is required: (i) the implicit individual utility function be linear; (ii) constraints on the dependence between the two sources of unobservable terms and the observed individual-specific and locationspecific variables; (iii) constraints on the dependence between unobservable terms and the observed individual-specific and location-specific variables. Also, the underlying conditional probability for individual crime commission is implicitly characterized by a linear probability model, which also introduces further constraints on the implicit random utility function. 
in a predetermined range of ages in each collective, and the GDP per capita, among other things.

Our empirical specifications, using $l$ and $t$ to index provinces and years, respectively, are written as follows

$$
C_{l, t}=\rho C_{l, t-1}+\beta^{\prime} Z_{l, t}+\eta_{l}+\alpha_{t}+u_{l, t}
$$

where $C$ represents the crime rate, and $Z$ is the covariates affecting this rate. The last three terms represent unobserved variables that capture province-level unobserved heterogeneity, aggregate shocks common to all provinces, and a term that comprises idiosyncratic shocks, measurement errors in the dependent variable, and aggregation errors. Even though in the individual-level model the covariates might be uncorrelated with the unobserved factors, the RHS variables in the aggregate regression are potentially correlated with the unobservable variables.

Given the features of the different unobserved components, we propose the following strategy. First, assuming that province-level unobserved heterogeneity is invariant over time, we can exploit the longitudinal data structure, and apply a fixed effects transformation to remove this unobserved component. Namely, denoting $\Delta$ as the firstdifferences operator, ${ }^{11}$ the fixed-effects transformation yields the following model:

$$
\Delta C_{l, t}=\rho \Delta C_{l, t-1}+\beta^{\prime} \Delta Z_{l, t}+\Delta \alpha_{t}+\Delta u_{l, t}
$$

where all the variables are now expressed in first-differences, but the parameters of interest are kept invariant. Second, the potential endogeneity between the covariates and the unobserved idiosyncratic term $u_{1, t}$ remains after the fixed-effects transformation. Consequently, the covariates must be instrumented for. It is not obvious, though, whether there exist external valid instruments, consisting of variables not included in the model but uncorrelated with the unobserved components. ${ }^{12}$ Most often, the obvious

\footnotetext{
11 For any variable $V_{l, t}, \Delta V_{l, t}=V_{l, t}-V_{l, t-1}$.

12 In the search for appropriate instruments external to the model, in the case of immigration variables, which are of our main concern, we should look for variables highly correlated with immigration while exogenous to our model. Among the potential
} 
instruments are the lagged explanatory variables, which are not correlated with the current realizations of the error term.

Our estimation approach consists of a generalized method of moments (GMM) estimator (see Hansen, 1982; Arellano and Bond 1991). We consider a system-GMM estimator proposed by Arellano and Bover (1995) and developed by Blundell and Bond (1998). Given the small sample size, the standard errors must be appropriately corrected from potential finitesample biases following Windmeijer (2004).

\section{Discussion of Results}

In table 3 , we present the descriptive statistics of our endogenous variables. We use four measures of criminal activity. The first variable is total crime infractions, including felonies and misdemeanors. ${ }^{13}$ The second variable is felonies only. ${ }^{14}$ The third variable is misdemeanors only (crimes less serious than a felony). Property crimes, the last variable, involve the taking of money or property without violence or threat of violence against a victim (included in felonies). ${ }^{15}$ We can see that misdemeanors (which are

candidates, we can think of the province-level weight of services and construction sectors in GDP, the investment expenditure in public infrastructures, and the share of employment in low-skilled industries. Given the high level of participation of immigrants in such economic activities, such potential instruments are positively correlated with the proportion of immigrants in province populations. However, its exogenous nature is under question, to the extent that the higher these variables, the higher the immigrants' opportunities in the legal sector, what might affect the immigrants' propensity to be involved in the crime sector.

13 We produce results for the total crime rate because it has been used very often in previous related studies. However, we believe that the total crime rate is not very informative since it aggregates too many different activities concerning under-compliance with the law: violent crimes, organized crime, property crime, administrative infractions and misdemeanors. When using the total crime rate, we are weighting uniformly all these activities, irrespective of their type (in fact, we could argue that it is unclear how the weights should be determined). Also we are implicitly imposing that a change in any righthand-side variable of the econometric model leads to a certain increase/decrease in the number infractions, irrespective of their nature.

14 Under Spanish criminal law, it includes property crimes, crimes against people (homicides, injuries), crimes against freedom and collective security (drugs, road traffic), crimes against the government and the courts (mainly noncompliance with judicial decisions) and public order.

15 This is probably the cleanest measure of crime for statistical purposes out of the four we use and the one most easily related to the economic model. However, since our hypothesis is also related to noneconomic variables, in particular cultural proximity, it seems to us more 
mostly punished with administrative penalties) are more numerous on average whereas property crimes exhibit a larger relative dispersion.

\section{<INSERT TABLE 3 HERE>}

There are good cautious reasons to use four measures of criminal activity. All capture criminal behavior although they might exhibit a different pattern. Felonies have increased only slightly during this period, whereas the misdemeanors have rapidly increased. Moreover, there might be a substitution effect in property crime, where immigrants could have replaced natives. Furthermore, property crimes could adhere to economic models more easily than other crimes. Finally, there have been legal changes during the sample period that have transformed misdemeanors into felonies, which justify why we should look at the total crime rate just to make sure our results are not contaminated by legal reform. ${ }^{16}$

As explanatory variables related to immigration, we consider the proportion of immigrants to the province's total population. Additionally, we consider the proportion of immigrants that speak Spanish as a native language and those whose nationality is from the European Union before the expansions that occurred during this decade (EU15). These last two variables were considered because of their quantitative importance (although their share of total immigration has been decreasing in the sample period). The specific consideration of immigrants from different nationalities should control for different attitudes among these groups. ${ }^{17}$

comprehensive and technically more competent to test also the other two variables, felonies and misdemeanors.

16 The reason why we do not use the homicides rate, the best feasible measure of crime for regression analysis, as a possible dependent variable is due to the small numbers as evident from Table 2 and small annual variations. According to the Spanish Ministry of Interior, in 2006 there were 570 homicides, 436 committed by Spanish citizens and 134 by foreigners. These numbers compare with 470 homicides in 2000, 373 committed by Spanish citizens and ninety-seven by foreigners.

17 Unfortunately, the lack of representativeness of other immigrants of different countries of origin in low populated provinces has precluded us to control for more disaggregated measures of immigration. 
To account for the effect of living in large urban agglomerations, we have considered the percentage of province population living in cities with at least 100 thousand and 500 thousand inhabitants. Another characteristic that we use is the GDP per capita and the rate of unemployment in the province. These two variables provide a measure of economic legitimate opportunities. The hypothesis is that better economic opportunities in the legal labor market make criminal activity less attractive.

We also use measures to control for differences among immigrants and natives. We use the corresponding proportions of immigrants and natives which have completed at least secondary education. Unfortunately, given the lack of representativeness of these collectives in provinces with small population, we have used data at the regional level from the Spanish Labor Force Survey. Consequently, we cannot exploit the variability across provinces of the same region. This same data source has been exploited to calculate, at the regional level, the proportion of young male natives and immigrants, respectively, for which we have considered separately two age cohorts, fifteen to twenty-four and twenty-five to thirty-four years old. Table 4 summarizes the descriptive statistics for the explanatory variables.

\section{$<$ INSERT TABLE 4 HERE $>$}

For every measure of crime rate, we have considered three different estimation methods, which are presented in Table 5. ${ }^{18}$

\section{$<$ INSERT TABLE 5 HERE $>$}

As a benchmark, we consider the OLS estimations of the untransformed model. For the aforementioned reasons, such estimates are expected to be inconsistent because of the correlation between unobserved

18 With respect to misdemeanors, a legal reform, performed in 2003, turned a great part of the misdemeanors related to physical aggression and threats, particularly among family members, to felonies with criminal consequences. The inclusion of year binary dummies allows us to control for this legal change. 
province-level characteristics and the covariates. We also report the withingroups estimations, which consist of least squares estimates of a fixed-effect transformation of the aggregate model. Even though the within-groups transformation removes the unobserved time-invariant province effects, the resulting estimates might not be consistent if the variables are not strictly exogenous, which is not held for the reasons explained earlier. Either way, we report both OLS and within-groups estimates for the purpose of comparison. Last, we report the system-GMM results, in which the instrument set is composed of the second and third lags of the explanatory variables.

In order to assess the quality of the GMM estimates, we have used two types of specification tests, the Hansen-Sargan test to check for the validity of the instrument set, and the $\operatorname{AR}(2)$ test of error autocorrelation. The latter test does not show any evidence of error within the specifications in any of the cases. However, the Hansen-Sargan test seems to reject the specifications in the case of total crime. With respect to total crimes, which include both felonies and misdemeanors, the aggregation of remarkably different infractions is the most likely reason for the rejection of the specification. Namely, we are aggregating offenses that are very different in nature, implicitly supposing that the effect of the explanatory variables is simply proportional to the number of different illegal activities. On the other hand, the specification tests for felonies and property crimes behave well.

In the case of total crimes, OLS estimates exhibit that the presence of immigrants is positive and significant, but being a Spanish speaking (Latin American) immigrant offsets the positive effect of being an immigrant on crime. However, when we consider the within-groups and, more importantly, the GMM estimates, the coefficients on the immigrant shares keep their signs but are no longer significant. In fact, the lagged total crime rate is the only significant variable in the GMM estimates. This fact, together with the Hansen-Sargan test, whose low p-value casts doubt on the validity of the specification, behind which underlies the aggregation of remarkably different crime infractions, with very different attitudes and 
behavioral issues behind them. This result suggests a focus on different types of infractions, namely the three that we have proposed earlier.

The main estimation results obtained for the different crime types can be summarized as follows. First, variations in the presence of immigrants at the different provinces have a significant impact. Second, there is a differential attitude towards crime across different immigrants by geographical area of origin and personal characteristics. Third, previous crime history, captured by the lagged crime rate, has a substantial effect.

Regarding the estimated effect of total immigration, OLS estimates of the share of immigrants in the total population is positive and significant for every type of crime considered. This implies that the rise in immigration increases crime, even after controlling for observable characteristics like the economic conditions and the composition of the population. However, when considering the within-group estimates, the estimated effect becomes nonsignificant. However, neither the OLS nor the within-group estimators account properly for the potential endogeneity problems. Our GMM estimations confirm the importance of immigration when explaining crime during this period, yet the effects are different both at the qualitative and the quantitative level. In the case of misdemeanors, the share of immigrants is still positive but not significant.

The estimations also corroborate our hypothesis concerning different behavior of the different groups of immigrants based on geographical area of origin. ${ }^{19}$ The models that account for the shares of immigrant population who speak Spanish as a native language (mostly Latin American immigrants), on the one hand, or come from one of the EU15 countries, on the other hand, are particularly relevant. These variables ought to be interpreted as an additional effect given the characteristics already controlled, specially being an immigrant. For all crime types, being a Spanish speaking immigrant reduces the likelihood of criminal activity in

${ }^{19}$ We have concentrated on these two groups of immigrants by geographical area of origin since they are very representative in most of the provinces considered. The fact that the representativeness of many other groups of immigrants from other countries is very unequal has prevented us from controlling for further areas of origin. 
an important and significant way, although the precision of such an estimate is reduced for misdemeanors. To a lower extent, being an EU15 immigrant also appears to reduce the propensity to commit crime, but both the magnitude and the precision of the estimated effect for this group of immigrants is much lower.

We have also controlled for the percentage of immigrants and natives who have completed at least secondary education. Its significance and interpretation appear ambiguous. Given the importance of Latin American immigrants, we have also accounted for the percentage in this group who has completed at least secondary education, finding a negative but clearly non-significant effect for property crimes and misdemeanors. Together with the general result concerning Spanish speaking immigrants, we can interpret our results as showing that the cultural proximity of this group to the native population has played an outstanding role in explaining the exceptional case of Spain.

The lagged crime rate exhibits a significantly positive effect, being close to unity (but clearly below one for all crime types), which suggests a substantial inertia in crime dynamics. We interpret this result as the importance of the learning curve in crime propensity. Interestingly, the highest inertia is found for misdemeanors and, to a lesser extent, property crimes, being lower for felonies, which are precisely the crime types for which economic reasons need not play a major role.

Concerning the remaining variables, we observe that, in line with the economic model of crime, the GMM estimates for GDP per capita exhibit a negative effect, although not significant. On the other hand, the estimates of province unemployment rate are very imprecise. ${ }^{20}$

We have also controlled for the proportion of people living in highly populated areas, by means of the variables indicating the proportion of the

${ }^{20}$ Ideally, we would like to consider unemployment rates in the province for natives and immigrants. Nevertheless, the level of representativeness for immigrants was very poor for underpopulated provinces, and even for some underpopulated regions. Therefore, we have opted out of using province unemployment rates as a measure of employment opportunities for both natives and immigrants. 
province population living in cities above 100 thousand and 500 thousand inhabitants. These variables are intending to capture the difficulty of detection and the less likelihood of strong ethnic ties, as measured by the size of the population. Although not significant, if anything, we find that such effect is positive, especially for felonies, in line with the evidence that population density favors crime as it hardens crime prosecution.

Finally, given that most crimes are committed by young males, we have considered the percentage of male natives and immigrants aged between fifteen and twenty-four, and between twenty-five and thirty-four. We find that, in the case of property crimes and misdemeanors, the percentage of male immigrants aged between twenty-five and thirty-four years is statistically significant, indicating that age and gender may affect an individual's propensity to commit crimes. It must be noted, as seen in Table 4 , that the share of young males is much higher for immigrants than for natives.

We have also considered alternative specifications in order to assess the robustness of our results. First, we have considered alternative instrument sets to gauge the sensitivity of our results to the inclusion of different lags of the covariates in the instrument set. Second, we have considered a nonlinear transformation of the crime rate, to evaluate the robustness of our results to departures of the underlying linear probability model at the individual level. Third, we have considered a static specification, which excluded the lagged crime rate.

The results, not reported here (but available upon request), can be summarized as follows. First, changes in the instrument set, particularly the lags of the explanatory variables included, mostly affected the precision of the estimates while the main qualitative results remain. Second, defining a nonlinear transformation of the crime rate, which is consistent with an underlying logistic distribution of the individual probability of committing crime, the qualitative results are kept. However, we have opted out of our specification, since the interpretation of estimation is clearer. Last, regarding the static model, ignoring the lagged crime rate led to a clear 
rejection of the specification, except for misdemeanors, and the precision of the estimates, particularly for the immigrant shares, was substantially reduced.

In summary, our results largely confirm the hypothesis that we have developed before and are consistent with the economic literature.

\section{Conclusions}

The present work introduces a first comprehensive analysis of the relationship between immigration and crime in Spain. In the context of the EU, Spain is not a country with high crime rates. During the last decade of significant immigration, Spain has seen an important rise in crime at a similar pace with its immigrant population, but to a lower rate than other countries. We hypothesize that the explanation of this behavior is related to the individual characteristics of the immigrants that Spain has received. We argue that it is not so much the number of immigrants but the specific characteristics that seem to explain the relationship between crime and immigration in Spain.

In this respect, cultural proximity and education must be specially noted. Immigrants from some populous groups, such as those who are Spanish native speaking, present a substantial proportion of people with at least secondary education, for whom criminality is much lower. This effect has contributed decisively to avoid any kind of explosion of criminality. Gender has also positively contributed to this effect. In fact, even after controlling by gender and education, we can still conclude that Latin American immigration has probably undermined the potential rise of criminal rates in Spain. This result also happens, to a lesser extent, with EU15 immigrants. Our result is fully consistent with the evidence for the United States regarding Mexican immigrants (known as the Latino Paradox), where immigration from Mexico has lowered crime rates in some areas. $^{21}$

${ }^{21}$ See, for example, the discussion by Sampson (2008) and references therein. 
Other immigrant groups with lower education levels have contributed significantly to the rise in crime rates. It must also be noted that these immigrants started at arrival with a crime rate significantly higher than Spanish nationals, but have been converging as their size and composition changed. It must be noted the specific case of the Romanian immigrant group, now one the most numerous in Spain. Even though it started with high crime rates, nowadays it presents lower rates than nationals in the twenty-fifty age group.

This work also provides for a good example of standard discussions in the econometrics of crime. We have observed how the booming stage of the business cycle in Spain reduced crime because it increased the opportunity cost; we have seen that population density favors crime because it makes harder the identification and tracking of criminals; we have concluded that crime is concentrated among young males and lesser-educated individuals. The implications of this work for designing public policies are clear. Immigration is not a simple homogeneous phenomenon and must not be treated as such. Public authorities should respond with differentiated policies, depending on the relevant characteristics. 


\section{References}

Arellano, M. and Bover, O., 1995. Another look at the instrumentalvariable estimation of error components models. Journal of Econometrics 68, 29-52.

Arellano, M. and Bond, S., 1991. Some tests of specification for panel data: Monte Carlo evidence and application to employment equation. Review of Economic Studies 58, 277-97.

Becker, G., 1968, Crime and punishment: An economic approach, Journal of Political Economy 76, 169-217.

Bianchi, M., Buonanno, P., and Pinotti, P., 2008, Do immigrants cause crime?, Working Paper 2008-05, Paris School of Economics.

Blundell, R. and Bond, S., 1998. Initial conditions and moment restrictions in dynamic panel data models. Journal of Econometrics 87, 115-43.

Borjas, G. J., Grogger, J., and G. H. Hanson (2006), Immigration and African-American employment opportunities: The response of wages, employment, and incarceration to labor supply shocks, NBER Working Paper No. 12518.

Buonanno, P., and D. Montolio, 2008, Identifying the socio-economic and demographic determinants of crime across Spanish provinces, International Review of Law and Economics 28 (2), 89-97.

Buonanno, P., Montolio, D., and P. Vanin, 2009, Does social capital reduce crime?, Journal of Law and Economics, forthcoming.

Butcher, K. F., and A. M. Piehl, 1998a, Cross-city evidence on the relationship between immigration and crime, Journal of Policy
Analysis and Management 17, p. 457-93.

Butcher, K. F., and A. M. Piehl, (1998b), Recent immigrants: Unexpected implications for crime and incarceration, Industrial and Labor Relations Review 51, p. 65479.

Butcher, K. F., and A. M. Piehl (2005), Why are immigrants' incarceration rates so low? Evidence on selective immigration, deterrence, and deportation. Federal Reserve Bank of Chicago WP-05-19.

Calvó-Armengol A. and Zenou Y., 2003, Does crime affect unemployment? The role of social networks, Annales d'Economie et Statistique, $N^{\circ}$ 71-72.

Card, D., (2001), Immigrant inflows, native outflows, and the local labor market impacts of higher immigration, Journal of Labor Economics 19, p. 22-64.

Chiricos T., 1987, Rates if crime and unemployment: An analysis of aggregate research evidence, Social Problems, 34, p. 187-211.

Dharmapala, D., and Garoupa, N., 2004, Penalty enhancements for hate crimes: An economic analysis, American Law and Economics Review 6, 185-207.

Durlauf, S.N., Navarro, S., and Rivers, D.A., 2010, Understanding aggregate crime regressions. Journal of Econometrics 158, 306-17.

Ehrlich, I., 1973, Participation in illegal activities: A theoretical and empirical investigation. Journal of Political Economy 81 (3), 521-65.

Fajnzylber, P., Lederman, D. and N. Loayza, 2002. Inequality and violent 
crime. Journal of Law and Economics 45, 1-40.

Freeman R.B., 1999, The economics of crime, in Handbook of Labor Economics, O. Ashenfelter and D. Cards (Eds.), Amsterdam: North Holland, p. 3529-571.

Garoupa, N., 1997, The theory of optimal law enforcement, Journal of Economic Surveys 11, 267-95.

Garoupa, N., 2007, Optimal law enforcement and criminal organization, Journal of Economic Behavior and Organization 63, 46174.

Glaeser, E.L., Sacerdote, B. and J.A. Scheinkman, 1996. Crime and social interactions. Quarterly Journal of Economics 111, 507-48.

Gould E., Weinberg B. and Mustard D., 2002, Crime and local labor market opportunities in the United States: 1979-1997, Review of Economics and Statistics. February 2002, 84(1): 45-61.

Grogger, J., 1995. The effect of arrest on the employment and earnings of young men. Quarterly Journal of Economics 110, 51-72.

Hansen, L.P. 1982. Large sample properties of generalized method of moments estimators. Econometrica 50, 1029-054.

Levitt S. D., 2001, Alternative strategies for identifying the link between unemployment and crime. Journal of Quantitative Criminology, vol. 17, $\mathrm{n}^{\circ}$ 4, December 2001.

Levitt, S. D., and Miles, T., 2007, Empirical study of criminal punishment, in Handbook of Law and Economics, A. M. Polinsky and S. Shavell (Eds.), Amsterdam: North Holland, p. 455-95.
McAdams, R., 2000, A focal point theory of expressive law, Virginia Law Review 86, 1649-729.

Moehling, C. and A. M. Piehl (2007), Immigration and crime in early 20th century America, NBER Working Paper No. 13576.

Polinsky, A. M. and Shavell, S., 2000, The economic theory of public enforcement of the law, Journal of Economic Literature 38, 45-76.

Raphael S., Winter-Ebmer R., 2001, Identifying the effect of unemployment on crime. Journal of Law and Statistics, vol. XLIV (April 2001).

Sah, R.K., 1991. Social osmosis and patterns of crime. Journal of Political Economy 99, 1271-295.

Sampson, R. J., 2008. Rethinking crime and immigration, Contexts 7, 28-33.

Windmeijer, F. 2004. A finite sample correction for the variance of linear efficient two-step GMM estimators. Journal of Econometrics 126(1), 2551. 
Figure 1

Variation of Crime and Unemployment in Spain, 2000-2006

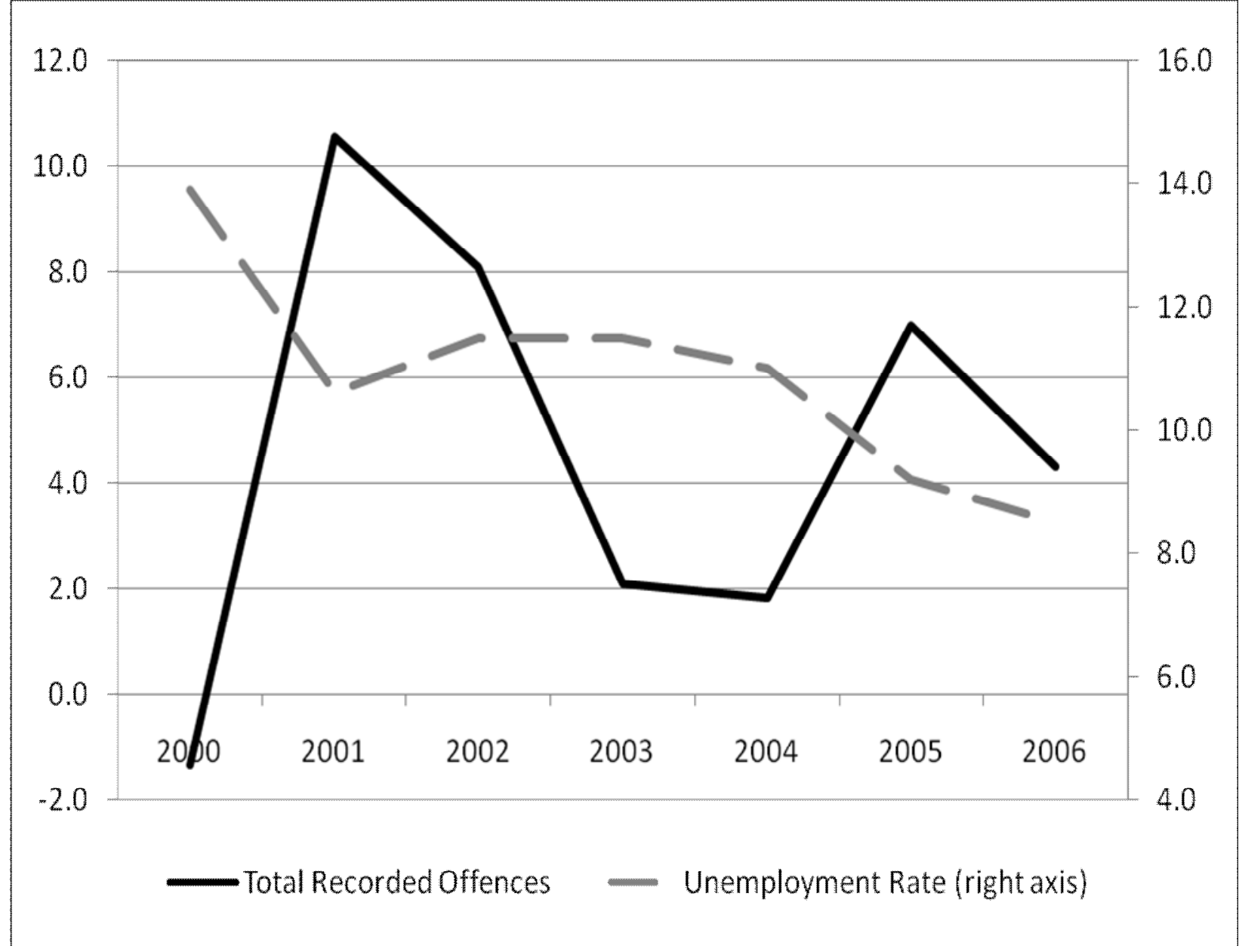


Table 1

Homicide Rates in Spain and the Country of Origin

Homicide Rate in Homicide Rate in

Ratio (A) / (B)

Spain (A)

the Native

Country (B)

\begin{tabular}{ccccc}
\hline \hline Europe & United & 14.8 & 1.5 & 9.6 \\
& $\begin{array}{c}\text { Kingdom } \\
\text { Romania }\end{array}$ & 26.7 & 2.4 & 10.9 \\
& Algeria & 98.7 & 1.7 & 56.9 \\
Africa & Morocco & 30.8 & 0.5 & 64.8 \\
& Colombia & 29.1 & 59.3 & 0.5 \\
\hline America & Ecuador & 13.1 & 17.0 & 0.8 \\
& Peru & 5.5 & 4.9 & 1.1 \\
\hline Asia & China & 14.3 & &
\end{tabular}

Source: MIR (Spain), INE (Spain) and UN Office on Drugs and Crime.

Note: The homicide rate (A) is the ration of number of homicides committed by immigrants in Spain per 1,000,000 population (average 2000-2006); the homicide rate (B) is the ratio of the number of homicides in the native country per 1,000 population (1999). 
Table 2

Crime Rates in Spain and the Country of Origin, average 2000-2006 Homicide Battery Burglary Theft Drug Traffic

\begin{tabular}{cccccc}
\hline \hline $\begin{array}{c}\text { United } \\
\text { Kingdom }\end{array}$ & 0.8 & 5.8 & 5.6 & 2.8 & 6.0 \\
Romania & 0.4 & 3.5 & 24.2 & 21.8 & 0.9 \\
\hline Algeria & 1.1 & 5.6 & 57.7 & 33.1 & 12.6 \\
Morocco & 0.6 & 4.6 & 11.9 & 12.0 & 11.7 \\
\hline Colombia & 0.8 & 3.0 & 5.0 & 3.3 & 11.0 \\
Ecuador & 0.3 & 2.8 & 1.5 & 2.6 & 0.7 \\
Peru & 0.2 & 1.9 & 0.5 & 0.6 & 0.7 \\
\hline China & 0.4 & 1.5 & & 0.6 & 0.1 \\
\hline
\end{tabular}

Source: MIR and INE

Note: The crime rate is the ratio of arrested persons per 1,000 population of age $20-50$. 
Table 3

Descriptive Statistics: Crime Rates

(number of crimes per 10,000 inhabitants - provincial data)

\begin{tabular}{lrrrrr}
\hline & Obs & Mean & Std. Dev. & Min. & Max. \\
\hline \hline Felony Rate & 450 & 200 & 112 & 53 & 722 \\
Property Crime Rate & 450 & 155 & 90 & 36 & 496 \\
Misdemeanors Rate & 450 & 204 & 79 & 56 & 494 \\
Crime Rate & 450 & 399 & 180 & 110 & 1139 \\
\hline
\end{tabular}


Table 4

Descriptive Statistics of Explanatory Variables

\begin{tabular}{lrrrrr}
\hline & Obs & Mean & Std. Dev. & Min. & Max. \\
\hline \hline \% Immigrants & 450 & 4.7 & 4.3 & 0.3 & 21.5 \\
\% Spanish speaking immigrants & 450 & 28.2 & 21.3 & 0 & 76.0 \\
\% EU-15 immigrants & 450 & 5.4 & 15.3 & 0 & 71.4 \\
\% pop. in cities > 100,000 inhab. & 450 & 17.7 & 4.6 & 9.2 & 34.0 \\
\% pop. in cities > 500,000 inhab. & 450 & 10.9 & 5.2 & 2.2 & 33.3 \\
GDP per capita & 450 & 17.7 & 4.6 & 9.2 & 34.0 \\
Unemployment Rate & 450 & 10.9 & 5.2 & 2.2 & 33.3 \\
\% natives w/ secondary educ. & 450 & 59.0 & 6.0 & 46.7 & 74.3 \\
\% immigrants w/ secondary educ. & 450 & 68.3 & 9.8 & 24.4 & 92.2 \\
\% Spanish speaking immigrants w/ & 450 & 76.4 & 8.4 & 41.8 & 100.0 \\
secondary educ. & & & & & \\
\% Male natives aged 15-24 & 450 & 13.3 & 1.9 & 9.5 & 18.6 \\
\% Male natives aged 25-34 & 450 & 16.1 & 1.5 & 12.5 & 20.7 \\
\% Male Immigrants aged 15-24 & 450 & 15.5 & 2.8 & 8.1 & 22.4 \\
\% Male Immigrants aged 25-34 & 450 & 30.3 & 5.7 & 11.1 & 40.4 \\
\hline
\end{tabular}


Table 5

Estimations for Crime Rates

Total crime rates

Felony rates

Property crime rates

Misdemeanor rates

\begin{tabular}{|c|c|c|c|c|c|c|c|c|c|c|c|}
\hline OLS & Within & GMM & OLS & Within & GMM & OLS & Within & GMM & OLS & Within & GMM \\
\hline $4.38^{\dagger}$ & 9.09 & 6.86 & $3.43 \S$ & $5.38^{*}$ & $8.69 \S$ & $2.97 \S$ & 4.17 & $7.05^{\dagger}$ & $1.48^{\dagger}$ & 4.55 & 4.11 \\
\hline 2.32 & 7.30 & 8.51 & 1.53 & 3.64 & 3.62 & 1.27 & 3.36 & 3.60 & 0.88 & 4.12 & 3.29 \\
\hline$-7.24^{\dagger}$ & -8.61 & -16.06 & $-5.98 \S$ & -4.89 & $-17.09 \S$ & $-5.50 \S$ & -5.14 & $-14.86 \S$ & $-2.27^{*}$ & -5.81 & $-14.42^{*}$ \\
\hline 3.84 & 12.77 & 18.65 & 2.58 & 6.49 & 6.67 & 2.24 & 6.46 & 7.42 & 1.67 & 7.46 & 9.56 \\
\hline-1.14 & -26.89 & -6.72 & -0.47 & $-19.18 \S$ & $-6.43^{*}$ & -0.09 & $-20.21 \S$ & -5.09 & 0.15 & -4.19 & 4.02 \\
\hline 2.78 & 14.09 & 11.16 & 1.62 & 7.67 & 4.53 & 1.53 & 6.74 & 4.19 & 1.33 & 7.62 & 5.24 \\
\hline-0.09 & -2.01 & 1.65 & -0.08 & -1.46 & $1.72^{*}$ & -0.07 & -1.65 & 1.24 & -0.04 & -0.34 & 0.70 \\
\hline 0.11 & 2.49 & 1.99 & 0.07 & 1.23 & 1.16 & 0.07 & 1.29 & 0.98 & 0.05 & 1.27 & 0.77 \\
\hline $0.42 \S$ & -8.79 & -0.18 & $0.19^{\dagger}$ & -1.67 & -0.29 & $0.20 \S$ & -0.27 & -0.21 & $0.20 \S$ & $-7.21^{*}$ & -0.19 \\
\hline 0.19 & 7.71 & 0.43 & 0.10 & 3.84 & 0.37 & 0.10 & 3.41 & 0.33 & 0.09 & 4.50 & 0.21 \\
\hline 2.48 & 13.45 & -3.47 & 0.75 & $4.99^{\dagger}$ & -5.56 & 0.66 & $4.69^{\dagger}$ & -4.47 & $1.75 \S$ & $7.80 \S$ & -0.98 \\
\hline 0.97 & 5.08 & 7.38 & 0.60 & 2.73 & 3.73 & 0.55 & 2.60 & 4.12 & 0.43 & 2.59 & 2.68 \\
\hline 0.08 & -2.03 & -1.26 & -0.19 & $-0.83^{*}$ & -0.97 & -0.09 & -0.50 & -0.42 & $0.61^{\dagger}$ & $-0.99^{*}$ & 0.16 \\
\hline 0.68 & 1.06 & 2.02 & 0.40 & 0.50 & 1.21 & 0.51 & 0.59 & 0.83 & 0.34 & 0.62 & 0.75 \\
\hline-0.02 & -1.34 & 0.89 & $0.56^{*}$ & -0.36 & 1.44 & 0.58 & -0.50 & 0.78 & $-0.54 \dagger$ & $-1.05^{*}$ & 0.63 \\
\hline 0.57 & 1.23 & 1.87 & 0.38 & 0.67 & 1.13 & 0.37 & 0.82 & 0.88 & 0.29 & 0.68 & 0.87 \\
\hline 0.38 & 0.42 & 0.95 & 0.11 & 0.20 & $0.78^{\dagger}$ & 0.17 & 0.24 & $0.94^{\dagger}$ & $0.23 \S$ & 0.22 & $0.47 \S$ \\
\hline 0.22 & 0.29 & 0.80 & 0.13 & 0.15 & 0.44 & 0.19 & 0.25 & 0.52 & 0.11 & 0.17 & 0.22 \\
\hline 0.00 & 0.05 & 0.22 & -0.03 & -0.04 & 0.09 & -0.10 & -0.15 & -0.19 & -0.05 & -0.01 & -0.12 \\
\hline 0.23 & 0.23 & 0.44 & 0.14 & 0.13 & 0.20 & 0.20 & 0.17 & 0.29 & 0.12 & 0.11 & 0.18 \\
\hline 7.97 & 26.57 & 1.13 & $3.44 \S$ & $12.87 \S$ & -6.01 & $3.07 \S$ & $14.27 \S$ & -6.79 & $3.09 \S$ & $9.98 \S$ & -1.37 \\
\hline 2.42 & 10.56 & 18.05 & 1.49 & 5.51 & 6.29 & 1.56 & 5.28 & 8.21 & 1.18 & 5.68 & 6.52 \\
\hline-0.93 & 11.88 & -18.78 & 0.83 & 5.28 & $-11.65^{*}$ & 0.22 & $6.78^{*}$ & $-7.97 \dagger$ & -0.88 & 3.21 & -8.57 \\
\hline 3.22 & 9.52 & 18.61 & 2.04 & 5.28 & 9.06 & 1.62 & 5.04 & 5.78 & 1.24 & 5.21 & 8.78 \\
\hline-0.42 & -2.45 & 2.36 & -0.13 & -1.75 & 1.33 & -0.02 & $-1.51^{*}$ & 0.33 & -0.17 & -0.93 & 1.06 \\
\hline 0.81 & 1.92 & 2.81 & 0.52 & 1.18 & 1.59 & 0.50 & 1.05 & 1.91 & 0.44 & 0.97 & 1.35 \\
\hline-0.02 & 3.49 & 1.38 & 0.05 & 1.83 & 0.33 & 0.12 & $2.13 \S$ & 0.64 & 0.09 & $1.63^{*}$ & $2.06^{\dagger}$ \\
\hline 0.42 & 1.94 & 1.48 & 0.26 & 0.99 & 0.81 & 0.30 & 1.02 & 0.65 & 0.23 & 1.04 & 1.06 \\
\hline 0.86 & 0.45 & $1.00 \S$ & $0.84 \S$ & 0.40 & $0.88 \S$ & $0.84 \S$ & $0.37 \S$ & $0.90 \S$ & $0.91 \S$ & $0.56 \S$ & $0.95 \S$ \\
\hline 0.06 & 0.08 & 0.12 & 0.07 & 0.09 & 0.16 & 0.06 & 0.08 & 0.13 & 0.04 & 0.06 & 0.09 \\
\hline & & 3.4 & & & 22.8 & & & 25.6 & & & 15.1 \\
\hline & & 32.7 & & & 46.0 & & & 37.7 & & & 29.7 \\
\hline
\end{tabular}

$\mathrm{AR}(2)$ test (\% p-value)

22.8
46.0

29.7 